\title{
Research on Japanese Teaching of Listening and Speaking Courses Based on CBI
}

\author{
Wei Zou \\ School of Foreign Studies, Xi’an University, Xi’an, Shaanxi, 710065
}

Keywords: Japanese teaching, Listening and speaking courses, CBI

\begin{abstract}
The training model of Japanese listening and speaking is a new attempt of teaching reform surrounding the college Japanese syllabus. It is one of the effective methods to improve the quality and level of college Japanese teaching. The model of CBI (Content Based Teaching), which combines subject knowledge with language skills training, has a strong feasibility in the teaching of Japanese listening and speaking courses. This paper discusses the application models of CBI in Japanese listening and speaking courses to provide some references for the relevant researchers.
\end{abstract}

\section{Introduction}

As a public compulsory basic course, college Japanese plays an important role in university education. With the development of Sino Japanese economic and trade, the demand for skilled Japanese talents is increasing, especially for outstanding Japanese speaking and listening talents. Therefore, the quality requirements for college Japanese teaching will also rise, which provides a new opportunity for the further development of college Japanese education. Facing the new situation and new requirements, how to improve the quality of college language teaching and how to use Japanese classroom teaching to train students to become the talents needed in twenty-first Century are all the focuses that our Japanese teachers are concerned about. The transformation of the concept of the subject of teaching is the key to the problem. The modern teaching idea advocates the teaching mode which takes teachers as the main body and the teacher is the dominant and the student is the main body. We can teach students in accordance with their aptitude by using various teaching methods such as creating situations, using multimedia and other teaching methods. After years of exploration, the listening and speaking ability of college students in our country has been greatly improved, but it is far away from the requirements of the teaching of Japanese courses in the university. Specific performance in: Although the teaching both ideologically attached great importance to the ability of listening and speaking after one or two semesters of training, most of the students can understand the teachers' classroom language, and can do some openings such as self-introduction, retelling texts such as a simple expression, but in the sense of language training, cultural knowledge and communication the rules are still poorly understood, not to mention the use of Japanese spoken language training to do a book report, text summary and presentations, the advanced form of. With the development of global integration and the further expansion of reform and opening, the requirements for College Japanese listening teaching have also been improved. However, the current college Japanese listening teaching is generally a skill training mode. Students generally have such problems as narrow knowledge and poor thinking ability. It is difficult to achieve the goal of effective communication in Japanese learning, work and social interaction. Therefore, in the current college Japanese speaking and speaking teaching, we need to change the original teaching idea and use new teaching methods to change the present situation.

\section{Introduction of CBI Teaching Model}

CBI (Content-based Instruction) is based on the content of the course of foreign language teaching is the language teaching and learning to master the subjects or learners interested in information combined with foreign or two language teaching philosophy, teaching method, teaching mode, is a 
kind of foreign language acquisition through subject teaching the teaching idea. Language is based on text and discourse. Content based teaching method holds that language units conveying information should be text or utterance longer than sentence length. Language use always has definite and specific purposes, and requires multiple skills combination. Content based teaching also advocates that two language or foreign language learning must have a real communicative purpose, which is interesting, challenging and consistent with the needs of students, and is closely related to students' experience. As far as teaching content is concerned, teaching is usually organized on a specific subject, and the development of multi-language skills is regarded because of incidental or natural. Content oriented teaching encourages students to learn independently, cooperative learning and one eye study. Teaching materials should be both authentic and teachable. The theory of Constructivism in cognitive psychology, based on Piaget's new and old knowledge connection, is also the theoretical basis of the content teaching method. According to the differences of teaching objectives, the teaching mode based on CBI concept mainly includes protection mode, auxiliary mode and theme pattern. The strong CBI mode is used to master the subject knowledge as the main purpose of the classroom, while the weak CBI mode is mainly used to cultivate learners' foreign language communicative competence. The CBI theme pattern belongs to the disadvantaged CBI model. But different from the traditional language teaching mode is the CBI thematic mode, which advocates that language teaching should use language as a medium and means to transmit knowledge, and carry out teaching around the content and information that students will learn. It integrates content with language learning, and transfers the focus of teaching from the learning language itself to the language skills of the learning content.

\section{Application Feasibility of CBI in Japanese Teaching of Listening and Speaking Courses}

The CBI teaching model uses real language materials. Text, video, audio and other teaching material should be selected to use the language to people from the original material. Students should use their own knowledge to learn and evaluate new information. CBI is suitable for the specific needs of the learners. The topics, materials and activities in the teaching must be suitable for the learners' language level, cognition and emotional needs. In foreign countries, the concept of CBI has been successfully applied to all kinds of teaching practices in the United States, Britain, Canada, Vietnam, Turkey and other countries. It is mainly used to integrate learners' language skills with teaching methods such as research learning, task based teaching and so on. For example, Ngan uses benchmarking test and questionnaire survey method to empirically study the application of CBI concept in Japanese Accounting Teaching in Vietnam finance and customs college, and proves the validity of CBI concept. The application of CBI Arslan's on the concept of Japanese Teaching in Turkey colleges and universities of science and Engineering in the preparatory classes for the empirical research, the result shows that the teaching is very good to meet the needs of the students learning Japanese, so that they have the necessary professional knowledge of Japanese language learning skills. Domestic scholars for the study of CBI teaching gradually from the introduction, comment to empirical research on College Business Japanese, Japanese, Japanese, British and American Literature in computer teaching. For example, National Social Science Fund Project "basic Japanese teaching content based curriculum system innovation and practice of the teaching concept in Japanese undergraduate basic stage of teaching practice and the feasibility of the application of teaching strategies such as large amount of empirical research. To sum up, domestic and foreign scholars have achieved fruitful results in the study of CBI teaching. However, there is little research on the CBI concept in the teaching of Japanese majors in newly established local universities. This article will take the Japanese professional undergraduate skills training as an example to explore the practical application of CBI concept in the teaching of Japanese professional skills courses. 


\section{Application Models of CBI in Japanese Teaching of Listening and Speaking Courses}

\subsection{Application Model before Class}

In specific teaching activities, teachers should consider the above particularities in terms of classroom goal setting, teaching content selection, teaching method selection, teaching activity design, etc. Teachers can arrange self-learning tasks such as background knowledge preparation, thematic vocabulary expansion, listening preheating, and thematic presentation through self-learning platform. The teacher assigned in this part of related tasks, such as the introduction of Japanese articles, news and other information, recommend relevant references and cyber source, ask the students to write reading notes record the relevant information, the meaning of the subject, policy information, economic development, exhibition services. The aim is to familiarize the students with the knowledge related to the selected topics and to reserve the knowledge for the listening and speaking exercises in the class. About language learning, students can choose common expressions according to the learning materials provided by teachers. They can also list common expressions, list the original sentences, translate them into Chinese or make lists of their problems as difficult sentences for discussion in class. The purpose of this task is to clear up the vocabulary and language expression barriers for the listening and speaking exercises in the class. The teachers in this part arranged before class listening tasks, the listening material around the selected theme, listening time in 2 minutes, students are required to understand the idea, pay attention to imitate the pronunciation and intonation of listening materials, focus on new words and difficult words pronunciation, word stress, liaison, weak reading pronunciation rules. Through this task, students can acquire the main information ability of listening materials under the premise of reading material and language input, help to enhance students' self-efficacy and enhance self-confidence, and at the same time, enhance students' grasp of pronunciation and intonation. The students in groups according to the materials, courseware, courseware contains the contents of the theme show two aspects and selected the theme of the quiz, the former introduces related background, current situation, relevant vocabulary, language expression, reference recommendation and other content, the latter is the theme around the selected problem set or difficult problems discussed.

\subsection{Application Model during Class}

Task is an activity that is directly related to language learning in language teaching. Japanese Listening and speaking course can cultivate students' listening and speaking ability. In content based teaching methods, we must never emphasize tasks mechanically and cultivate skills by task centered. This will abandon the original intention. The classroom teaching link can be composed of several main links: introduction, listening and speaking training and evaluation feedback. Teachers' teaching is centered on the development of students' abilities. Teachers play the role of guidance, inspiration, monitoring, replenishment and feedback, while students are the main body of exercises. First, in the classroom, the teachers randomly select the students to make a presentation on the subject. After 15 minutes, the other group members will be evaluated and supplemented, and then the teacher will make a summary and introduce the main content of this lesson, namely listening and speaking training activities. Then, during listening training, teachers set up dialogues, paragraphs and news listening exercises. In the oral training, teachers choose a listening material from above listening training session, re broadcast to the students listening, and this material set the language analysis, the topic of discussion, to blurt out link to fully mobilize the students to use the knowledge of language output according to the. First, in the parsing of language points, teachers throw out some words and phrases in the listening material, or make difficult sentences by students, which are analyzed by students in Japanese, and then teachers summarize and feedback. Then, in the stage of blurting out, students can do rehearsal exercises alone or two students do role-playing exercises. In the topic discussion link, the discussion problem can be set by the teacher or the problem that the students set up in the presentation of the introduction. The theme is the main idea that runs through the course. In 
the teaching of listening and speaking, one or two topics are selected for one semester. This textbook can be divided into three main topics: cultural theme, life theme and scientific knowledge theme. Before class, it is necessary to collect and collate the information before class according to the different topics to obtain the true content and the content that the students are really interested in. This can cultivate students' self-learning ability and meet the requirements of the syllabus. In class, students can play short plays or share their learning experiences according to their themes of interest, so as to deepen their understanding and learning of this topic and make them really use. In addition, this kind of exercise can enhance the students' cooperative learning ability.

\subsection{Application Model after Class}

$\mathrm{CBI}$ is a kind of student-centered teaching concept, pay attention to the learning process rather than the results, to guide the students to feel their progress in the learning process, to foster a positive learning emotion. After class, to consolidate the achievement of students, teachers can learn through the network platform listening and oral practice work. Listening can be individual choice and abstract writing form. Oral practice, can consider setting the oral composition, conversation exercises, students to complete their work by submitting the recording. The effect of students' learning evaluation by the formative evaluation and summative evaluation of the two parts. The former, homework, classroom performance evaluation and teaching reflection caused by students' listening and speaking; the latter is formed by the course examination and questionnaire survey of students. The course evaluation methods are divided into two parts written and practical examination, the focus is the practice part of the assessment. I heard the practice skill examination requires students to complete the scene some combination of listening and speaking tasks, such as listening to a dialogue, answer questions; or listen to the main content of a monologue paraphrase; or do the oral composition. The students mainly learn the questionnaire recognition of the effective teaching mode of students and the teachers put forward teaching suggestions. The formative evaluation results directly affect and guide the daily teaching, summative assessment provides improved ideas for future teaching. The network can bring fresh blood to the classroom teaching, make up some shortcomings of the classroom teaching, stimulate students' interest, also can cultivate students' autonomous learning ability. On the one hand allows students to search topics and topic related resources, on the other hand, teachers can also use the cyber source to enrich the classroom, get real words and text. The evaluation of students' learning effect is mainly or mid-term and final exam. This test cannot reflect the process of evaluation, can effectively evaluate the learning effect of students. Effective evaluation and process evaluation into the evaluation system of teaching materials, teachers can monitor the learning effect of students, students themselves through self-evaluation to understand their own learning.

\section{Conclusion}

Content Based Instruction is a kind of language learning and learning content integration teaching method. The application of this teaching method in Japanese listening teaching, not only can stimulate students' learning enthusiasm and interest, improve the students' listening and speaking ability, cultivate students' autonomous learning ability, but also can improve their comprehensive quality and competitive ability, which is helpful for the future study and life.

\section{References}

[1] Katagiri K. Progress of Vocabulary Size and Listening, Reading, and Speaking Proficiencies Among Japanese High School EFL Students Over a Three-Year Period [J]. Jlta Journal, 2013(16): 127-146.

[2] Wang Q. How to improve students' ability of listening and speaking ability in basic Japanese class[J]. Journal of Jiamusi Education Institute, 2011(5): 318-320.

[3] Ping Lv, Meng Jin. Investigation of Practice Skill Pattern in Listening and Speaking of College 
Japanese Education[J]. Journal of Northeast Normal University, 2011(6): 195-198.

[4] Sarja A, Nyman T, Ito H, et al. The foreign language teaching profession in Finnish and Japanese society: a sociocultural comparison[J]. Pedagogy, Culture \& Society, 2017, 25(2): 225-241. 